\title{
O ensino médio vai à Universidade: (re)conhecendo a biologia através da experiência científica
}

\author{
High school go to University: recognizing the biology through scientific \\ experience \\ Fernanda Tesch Coelho \\ Érica Duarte Silva \\ Juliana Castro Monteiro Pirovani
}

Resumo: O presente artigo apresenta uma atividade de extensão desenvolvida utilizando a experiência científica universitária como ferramenta estratégica de ensino de biologia e divulgação científica. A atividade foi realizada com 20 estudantes da $2^{a}$ série do Ensino Médio de uma Escola Estadual localizada no município de São Mateus-ES e desenvolvida na Universidade Federal do Espírito Santo (UFES) campus São Mateus. As visitas ocorram em dias e foram realizadas nos laboratórios de ensino e pesquisa de Zoologia, Botânica, Genética, Biologia Celular, Anatomia Humana e Ecologia, além do Herbário, Coleção Zoológica e Fazenda Experimental. Os estudantes acompanharam as pesquisas científicas desenvolvidas nos laboratórios, conheceram as metodologias utilizadas, participaram de atividades e procedimentos de laboratórios e discutiram a utilização da ciência para fins sociais. Ao término das visitas, os estudantes responderam a um questionário. Os alunos sentiram-se interessados e atraídos pelas experiências vivenciadas e apresentaram mudanças na percepção sobre Biologia. Após a visita, 89\% deles afirmaram gostar mais da Biologia e compreenderem melhor qual a importância da ciência no cotidiano. Neste sentido, a realização de atividades práticas voltadas para a experiência científica contribuiu para a aprendizagem, interesse e mudança de percepção dos alunos sobre a Biologia de modo que a ciência passou a ser compreendida como uma ferramenta de formação social.

Palavras-chave: Extensão universitária. Aula de laboratório. Experimentação científica. Ensino de Biologia.

\begin{abstract}
This article seeks to report an intervention activity developed using university scientific experience as a strategic tool for teaching biology and scientific dissemination. The activity was carried out with 20 high school students from a State School located in the city of São Mateus-ES and developed at the Federal University of Espírito Santo (UFES) - São Mateus campus. Visits took place in days and they were carried out in the teaching and research laboratories of Zoology, Botany, Genetics, Cell Biology, Human Anatomy and Ecology, in addition to the Herbarium, Zoological Collection and Experimental Farm. The students followed the technical-academic work and research carried out in the laboratories, got to know the methodologies used in scientific research, carried out technical research activities and procedures in the laboratories and discussed the use of science for social purposes. At the end of the visits, the students answered a questionnaire. The students felt interested and attracted by their experiences and presented changes in their perception of Biology. After the visit, $89 \%$ of them said they liked Biology more and better understood the importance of science in their daily lives. In this sense, the realization of practical activities aimed at scientific experience contributed to the learning, interest and change in the perception of students about Biology so that science came to be understood as a tool of social formation.
\end{abstract}


Keywords: University Extension. Laboratory lessons. Scientific experimentation. Biology teaching.

\section{Introdução}

A Ciência, apresentada de forma simplificada por Chassot (2003, p. 91), é "uma linguagem construída pelos homens e pelas mulheres para explicar o nosso mundo natural". O autor destaca a importância da compreensão da linguagem científica uma vez que esta nos leva a compreender a própria natureza e as transformações que vêm ocorrendo nela. Ao definirmos os objetos de cada uma das ciências conhecidas, como a física, a química, a geologia, dentre outras, compreendemos a diversidade de interações e interseções existentes entre esses objetos. A biologia, por exemplo, é a ciência que se dedica a estudar os seres vivos e as interações que estes realizam com o ambiente. Este objeto se relaciona diretamente com os objetos de estudo de outras ciências, formando teias complexas e extraordinárias de conhecimento.

Deste modo, conhecer a Ciência, em sua complexidade e suas aplicações, possibilita que esta seja percebida e compreendida pelas pessoas em seu cotidiano, tornando-as mais críticas e conscientes sobre os acontecimentos. Ser um cidadão letrado cientificamente, então, permite o "entendimento dos princípios básicos de fenômenos do cotidiano aprimorando a capacidade de tomada de decisão em questões relativas à ciência e tecnologia em que estejam diretamente envolvidos, sejam decisões pessoais ou de interesse público" (DEL PINO; FRISON, 2011, p. 38).

Os avanços nas áreas de Ciência e Tecnologia crescem continuamente e fazem parte do cotidiano de grande parte da população mundial. Neste contexto, e no que se refere à prática social, Medeiros e colaboradores (2017) apontam que o ensino de Biologia exerce uma função extremante relevante com o desenvolvimento da humanidade e, relacionado ao que diz Cachapuz e colaboradores (2005, p. 17), com "a formação de cidadãos susceptíveis de participar na tomada fundamentada de decisões em torno de problemas sociocientíficos e sociotecnológicos cada vez mais complexos". 
A divulgação e popularização dos conhecimentos produzidos pela Ciência são fundamentais no processo de desenvolvimento social. Moreira (2006, p. 11) descreve que:

Consideradas as características do mundo moderno, a educação informal, aí incluída a divulgação científica [...] tem adquirido importância crescente. Ela se processa por meio de instrumentos variados como os meios de comunicação, os centros e museus de ciência, os programas de extensão universitários, os eventos de divulgação, a educação à distância e outros.

As Universidades são locais de grande produção de conhecimento científico em decorrência das constantes pesquisas que são realizadas em diversas áreas. Por esse motivo, é papel também da universidade, numa sociedade globalizada, ser uma organização aberta, que interaja com a sociedade extrapolando os "muros" e as "ilhas do saber", para chegar ao homem comum, mediante um trabalho conjunto com os meios de comunicação (KUNSCH, 1996).

Diversas iniciativas que visam aproximar estudantes do Ensino Médio da Universidade têm sido realizadas no território brasileiro, incentivando os jovens ao ingresso no ensino superior, como o projeto "Universidade de Portas Abertas" (UPA) realizado pela Universidade de Campinas (UNICAMP) em Campinas - SP (http://www.upa.unicamp.br/); "Universidade Aberta" pela Universidade Federal de São Carlos (UFSCar) em São Carlos-SP (http://www.visite.ufscar.br/); "USP e as profissões" pela Universidade de São Paulo (USP) nos campis de São Paulo, Bauru, Lorena, Piracicaba, Pirassununga, Ribeirão Preto e São Carlos-SP (http://prceu.usp.br); "Universitário Por Um Dia" e "Mostra Universitária" na Universidade Federal de Viçosa-MG (http://www.redecsfvicosa.ufv.br/?page id=62) e "UFES de Portas Abertas" realizado pela Universidade Federal do Espírito Santo em Vitória - ES (http://proaeci.ufes.br/conheca-o-projeto).

No âmbito educacional, orientações governamentais como os Parâmetros Curriculares Nacionais (PCNs), Base Nacional Comum Curricular (BNCC), Currículo Básico Comum (CBC) surgem como indicadores de propostas curriculares e pedagógicas estabelecendo conhecimentos, 
competências e habilidades que desenvolvam o exercício da curiosidade intelectual, utilização da abordagem científica, a investigação, a reflexão, a análise crítica, a criatividade (BNCC, 2018). Porém, estas orientações, por décadas, têm sido um grande desafio para a educação brasileira. Krasilchik (2000) aponta que as modalidades didáticas usadas no ensino das disciplinas científicas, em especial, apesar de todas as mudanças, ainda seguem tendências de currículos tradicionalistas ou racionalistas acadêmicos.

Krasilchik (2008) afirma que a Biologia pode ser uma das disciplinas mais relevantes para os alunos ou uma das disciplinas mais insignificantes e pouco atraentes, porém a maneira como ela é ensinada que define isso. Fernandes (1998) já trazia em seu trabalho a concepção que os estudantes apresentam sobre a disciplina, relatando que a maioria deles vê a Biologia ofertada em sala como uma disciplina cheia de nomes, ciclos e tabelas que servem apenas para serem decorados, tornando-a desinteressante, superficial e monótona.

Nesta perspectiva, tornar o ensino de Biologia atraente e prazeroso se torna um desafio para os educadores. É importante que os professores promovam atividades que permitam que os estudantes conheçam ao menos alguns procedimentos (métodos) que são utilizados na realização das pesquisas científicas e compreendam que as informações que chegam para eles através dos livros didáticos são resultados dessas pesquisas. Tudo isso deve acontecer de forma contextualizada e conectada com a realidade vivenciada pelos estudantes dentro dos diversos contextos em que estão inseridos.

Deste modo, considerando o ensino de Biologia ofertado na educação básica e o papel social da Universidade na popularização da Ciência, permitir que estudantes conheçam a Biologia concretizada na prática, por meio dos trabalhos e pesquisas que são realizados - de forma a compreender os processos de produção de novos conhecimentos - pode permitir que estes compreendam como o conhecimento científico interfere em seu cotidiano e a importância em tê-lo, além de aumentar o interesse dos mesmos estimulandoos quanto à vida escolar e acadêmica. 
O objetivo central estabelecido foi permitir que os estudantes do ensino médio conhecessem a base científica da Biologia, por meio de visitas à Universidade, perpassando por espaços de ensino e pesquisa, como os laboratórios e outras áreas de experimentação, e verificar se essa aproximação gerou mudança na percepção dos mesmos acerca da Biologia e da produção do conhecimento científico.

\section{Percursos metodológicos}

Este trabalho é fruto de uma monografia executada em 2014 no curso de licenciatura em Ciências Biológicas da Universidade Federal do Espírito Santo (UFES) - campus São Mateus. O protocolo desse estudo foi aprovado pelo Comitê de Ética em Pesquisa desta mesma Universidade na data 13 de outubro de 2014 sob o $n^{\circ} 34441314.1 .0000 .5063$ respeitando os princípios éticos de pesquisa e guardando a identidade de todos os participantes.

Participaram da pesquisa 20 estudantes da $2^{\mathrm{a}}$ série do Ensino Médio de uma Escola Pública Estadual localizada no município de São Mateus, norte do estado do Espírito Santo. As atividades propostas foram realizadas na UFES campus São Mateus, localizada nesta mesma cidade.

Para o inicio do desenvolvimento desta atividade foi realizada uma roda de conversa com os estudantes a fim de que fossem identificadas suas percepções primárias sobre a Biologia e o conhecimento científico. Algumas das perguntas norteadoras do diálogo foram: 1) Você gosta de Biologia?; 2) Qual área da Biologia você mais gosta?; 3) Qual a sua visão geral sobre biologia? Os relatos dos estudantes foram sendo anotados em um diário de campo para que, posteriormente, pudessem ser descritos e analisados.

Após esta constatação inicial, durante três dias, os estudantes foram levados a UFES-campus São Mateus, em horário inverso ao seu turno escolar, para conhecerem laboratórios $\mathrm{e}$ as pesquisas que são realizadas na universidade e participarem de atividades práticas relacionadas às áreas da Biologia: zoologia, botânica, genética e biologia celular e, além disso, conhecerem a coleção botânica (herbário), a coleção zoológica, o laboratório de anatomia humana e a fazenda experimental. 
Os laboratórios de ensino visitados são utilizados pelos cursos de graduação em Ciências Biológicas (Bacharelado e Licenciatura), Enfermagem, Farmácia e Agronomia e os laboratórios de pesquisa pertencem ao Programa de Pós-graduação em Biodiversidade Tropical. Foi montando um cronograma (Quadro1) separando as visitas por áreas, visando facilitar a compreensão dos alunos.

Quadro 01: Laboratórios e locais visitados pelos estudantes do ensino médio durante as visitas na UFES - Campus São Mateus.

\begin{tabular}{|c|c|c|c|}
\hline & $1^{0} \mathrm{dia}$ & $2^{\circ} \mathrm{dia}$ & $3^{\circ} \mathrm{dia}$ \\
\hline \multirow{5}{*}{$\begin{array}{l}\text { Laboratórios e } \\
\text { Locais visitados }\end{array}$} & Lab. Zoologia & $\begin{array}{l}\text { Lab. Taxonomia e } \\
\text { Genética Vegetal }\end{array}$ & $\begin{array}{l}\text { Lab. Anatomia } \\
\text { Humana }\end{array}$ \\
\hline & $\begin{array}{l}\text { Lab. de Sistemática e } \\
\text { Ecologia de Insetos }\end{array}$ & $\begin{array}{c}\text { Lab. Ecologia de } \\
\text { Restinga e Mata } \\
\text { Atlântica }\end{array}$ & Lab. Microscopia \\
\hline & $\begin{array}{c}\text { Lab. Zoologia de } \\
\text { Vertebrados Aquáticos }\end{array}$ & Coleção Botânica & $\begin{array}{c}\text { Lab. Genética e } \\
\text { Conservação Animal }\end{array}$ \\
\hline & $\begin{array}{l}\text { Lab. Zoologia de } \\
\text { Vertebrados Terrestres }\end{array}$ & Orquidário & $\begin{array}{c}\text { Lab. Ecologia de } \\
\text { Restinga e Mata } \\
\text { Atlântica }\end{array}$ \\
\hline & Coleção Zoológica & $\begin{array}{l}\text { Lab. Ecofisiologia } \\
\text { Vegetal }\end{array}$ & $\begin{array}{c}\text { Fazenda } \\
\text { Experimental }\end{array}$ \\
\hline
\end{tabular}

Fonte: Autoria própria.

A duração média de permanência em cada laboratório/ambiente foi de 45 minutos a 1 hora $\mathrm{e}$ todos os procedimentos foram mediados por professores, técnicos e alunos da UFES e pela graduanda responsável pela atividade. As observações realizadas pela pesquisadora durante as visita e realizações das práticas foram registradas no diário de campo para auxiliar na apresentação e discussão dos resultados tal como foram realizados registros fotográficos. Para Araújo e colaboradores (2013, p. 54) "o diário tem sido empregado como modo de apresentação, descrição e ordenação das vivências e narrativas dos sujeitos do estudo e como um esforço para compreendê-las".

Ao final de toda visita, os estudantes participantes responderam a um questionário semiestruturado a fim que fossem analisadas suas percepções acerca da Biologia e sobre a importância do uso do conhecimento científico no cotidiano. O questionário apresentava perguntas como: 1) Depois de conhecer os projetos realizados na UFES você passou a gostar mais de Biologia? "sim", "não", "mais ou menos". Por quê?; 2) Qual área da Biologia você mais gostou 
de conhecer durante a visita?; 3) Como você vê a Ciência e sua importância depois da visita na UFES?

A análise consistiu na interpretação dos dados obtidos através da roda de conversa e observações registradas no diário de campo dialogando-os com as referências bibliográficas que embasaram a pesquisa. Organizou-se, assim, um texto descritivo de forma a revelar as percepções dos estudantes sobre a Biologia antes da visita à Universidade. Para a análise dos dados do questionário apresentados no Quadro 2, foi realizada a quantificação da frequência com que as alternativas "sim", "não", "mais ou menos" foram assinaladas no questionário e agrupado com as justificativas, sendo posteriormente discutidas à luz do referencial teórico.

\section{Resultados e discussão}

Atividades práticas são essenciais para a aprendizagem e desenvolvimento dos estudantes. Moreira e Diniz (2003) sinalizam a importância de aulas de laboratório com experiências práticas como estratégias que possibilitam maior compreensão dos fenômenos biológicos pelos estudantes, uma vez que, posteriormente, ampliam-se as discussões acerca da temática. Ribeiro e colaboradores (2020), em um trabalho semelhante ao nosso, conduziram estudantes do ensino médio à realização de práticas voltadas à Botânica na Universidade e evidenciam a importância de se proporcionar esta experiência aos estudantes.

Visita dos estudantes à UFES - campus São Mateus

A seguir, serão apresentadas as visitas dos estudantes aos laboratórios da UFES - campus São Mateus.

- Laboratório de Anatomia Humana

Os alunos receberam informações básicas sobre o corpo humano com o auxílio de modelos didáticos, como esqueletos e modelos de gesso (Figura 1A). Conheceram os principais ossos do corpo (Figura 1B), músculos, veias, artérias e nervos. Observaram fetos, cérebro e coração humanos conservados em formol. Os estudantes fizeram perguntas como: trâmites para as peças anatômicas serem cedidas à Universidade e manutenção das mesmas no 
laboratório; sobre investigação forense; sobre o funcionamento e desenvolvimento do corpo humano.

- Laboratório de Microscopia

Foram observadas lâminas de tecidos vegetais (epiderme foliar) e animais (ovário, testículo, fio de cabelo, intestino, cérebro) (Figuras 1C, D). Além disso, foram realizadas duas práticas: 1) raspagem de mucosa bucal e montagem de lâmina para visualização de células da boca; 2) Confecção de lâmina com epiderme da planta Tradescantia pallida var purpurea, também conhecida como trapoeraba roxa ou coração roxo.

Figura 1 - Alunos durante visitas aos laboratórios de Anatomia Humana e Microscopia. A) Alunos conhecendo os modelos de gesso no laboratório de Anatomia Humana. B) Esqueleto humano sintético visualizado pelos estudantes no laboratório de Anatomia Humana. C e D) Alunos manuseando microscópios e visualizando lâminas de tecidos animais e vegetais.

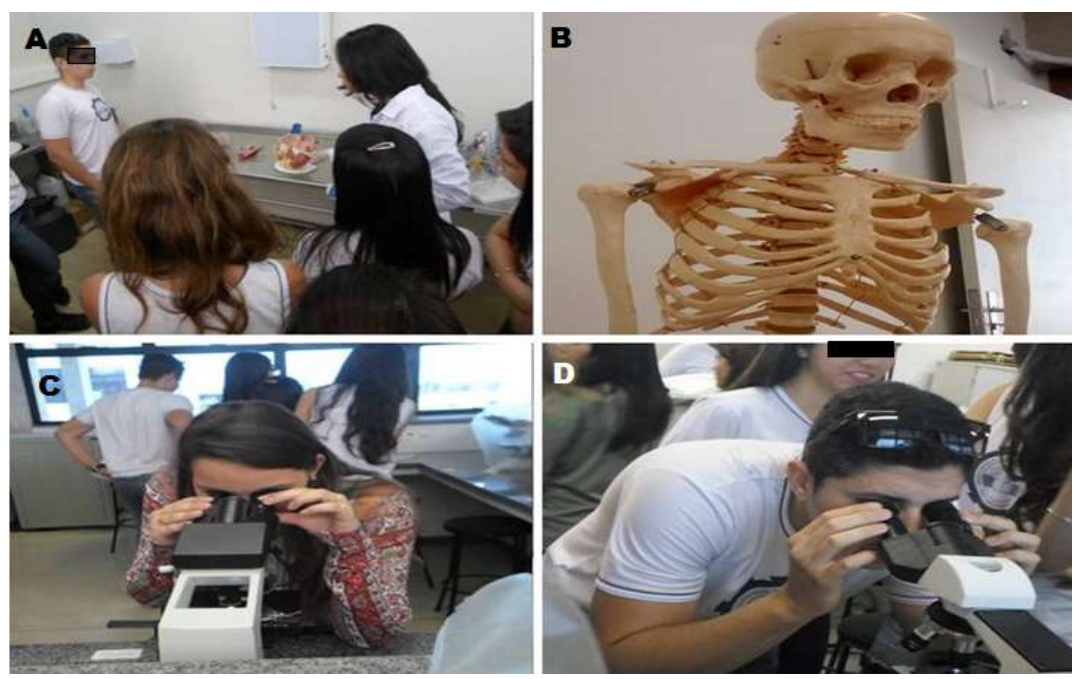

Fonte: Arquivo das autoras.

- Laboratório de Zoologia

Foram dadas aos estudantes noções de diversidade, taxonomia e ecologia de peixes marinhos. Abordou-se a importância dos estudos realizados com esses animais, os métodos de captura, triagem, identificação e estudos específicos (alimentação, reprodução, genética, etc) e mostrado diversos tipos de peixes marinhos (Figura $2 \mathrm{~A}$ ). Foi realizada uma prática de identificação de família utilizando chaves de identificação (Figura 2B), onde os alunos puderam observar estruturas dos peixes marinhos que não conheciam, aprendendo como é realizado o processo de identificação taxonômica e sua importância. 
Também foram expostos os outros espécimes de animais que estão armazenados no laboratório, como mamíferos, répteis e anfíbios. Por fim, foram entregues folhetos sobre o projeto "Meros do Brasil" e falado sobre a importância do projeto para a conservação dessa espécie.

- Laboratório de Fisiologia Vegetal

Foram realizadas as práticas: Teste de tetrazólio ${ }^{1} \mathrm{em}$ sementes de milho (Figura 2C) e cromatografia de pigmentos fotossintéticos (Figura 2D). Foi possível apresentar e discutir a importância dos estudos biológicos em fisiologia vegetal para as áreas agrícolas, uma vez que na região existem muitas culturas de interesse econômico como café, mamão e pimenta-do-reino.

Figura 2. Alunos nos laboratórios de Zoologia e Fisiologia Vegetal. A) Observação de peixes marinhos. B) Prática com a chave de identificação de peixes marinhos. C) Realização de Teste de tetrazólio em sementes de milho. D) Realização do teste de cromatografia de pigmentos fotossintéticos pelos alunos.
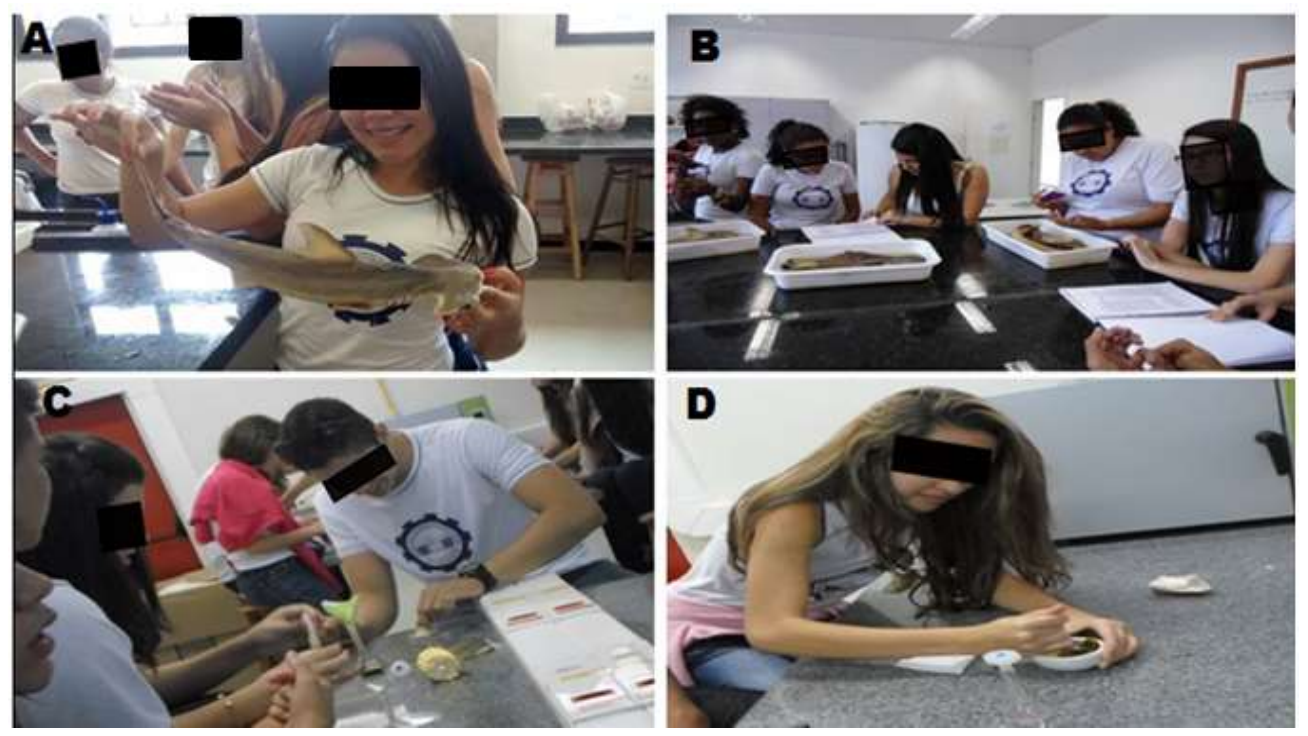

Fonte: Arquivo das autoras.

\section{- Laboratório de Sistemática e Ecologia de Insetos}

Durante a visita foi discutida a diversidade de invertebrados, principalmente artrópodes e o principal grupo de estudo do laboratório, os

\footnotetext{
$1 \mathrm{O}$ teste de tetrazólio baseia-se na atividade das enzimas desidrogenases as quais catalisam as reações respiratórias nas mitocôndrias, durante o ciclo de Krebs. Estas enzimas, particularmente a desidrogenase do ácido málico, reduzem o sal de tetrazólio (TCT) nos tecidos vivos. Quando a semente é imersa na solução incolor de TCT, esta é difundida através dos tecidos, ocorrendo nas células vivas a reação de redução que resulta na formação de um composto vermelho.
} 
insetos da ordem Ephemeroptera. Alguns exemplares foram observados a olho nu (Figura 3A) e com a utilização de estereomicroscópio (lupa) (Figura 3B). Além disso, alguns equipamentos e técnicas para a captura e triagem dos animais foram demonstrados e, posteriormente, os estudos sobre alimentação e taxonomia. Os temas ecologia e nomenclatura popular e científica foram discutidos entre estudantes do ensino médio, graduação e pós-graduação ao abordarem os insetos encontrados na região e suas importâncias ecológicas.

- Laboratório de Vertebrados Terrestres

Foram explorados assuntos como a diversidade de cobras (Figura $3 \mathrm{C}$ ) e mitos envolvendo esses animais, onde os alunos puderam dar relatos e tirar dúvidas. Várias espécies de cobras foram expostas para que os alunos pudessem conhecê-las (Figura 3D), uma vez que é um grupo temido e evitado por muitos. Também foram observados pequenos mamíferos taxidermizados, como lontra, gambá, roedores e marsupiais. Foi explicado como é realizado o processo de taxidermização ${ }^{2}$ e as diferenças entre modelos preparados para estudos e exposições. No final da visita, foi mencionada a importância do estudo da taxonomia dos ofídios para a produção de soro.

- Laboratório de Taxonomia e Genética Vegetal

Foram apresentados os projetos em taxonomia e sistemática, a metodologia aplicada, os estudos em diversidade de plantas terrestres e o sistema de classificação, abordando a importância de conhecê-las e classificálas como espécies, gêneros, famílias, etc. Os alunos receberam informações sobre os vegetais que são utilizados e consumidos no dia-a-dia, além de visualizarem e manipularem exsicatas ${ }^{3}$ (Figura $3 \mathrm{E}$ ) de várias espécies de plantas.

\footnotetext{
${ }^{2} \mathrm{~A}$ taxidermização ou taxidermia é o processo de dar forma à pele de animais mortos com a finalidade de deixar a sua aparência mais próxima de um animal vivo, podendo ser então, utilizado com fins didáticos ou científicos. Antigamente era empregado o termo empalhar para esse procedimento.

${ }^{3}$ Exsicata é uma amostra de planta prensada e em seguida seca em uma estufa (herborizada). Após a secagem a planta é fixada em uma cartolina de tamanho padrão acompanhada de uma etiqueta contendo informações sobre o vegetal e o local de coleta, para fins de estudos botânicos. Exsicatas são normalmente guardadas no herbário.
} 


\section{- Genética e Conservação Animal}

Os estudantes acompanharam alguns dos procedimentos realizados rotineiramente no laboratório, como a extração de DNA de golfinho, preparação de gel de agarose ${ }^{4}$ e corrida por eletroforese (Figura 3F). Posteriormente, foram apresentados os projetos de pesquisa desenvolvidos no laboratório de Genética e Conservação Animal e a importância deles para o desenvolvimento científico e social.

\section{- Laboratório de Ecologia de Restinga e Mata Atlântica}

Foram apresentados os trabalhos que são realizados na cidade de São Mateus e a importância para a conservação das áreas de restinga e Mata Atlântica da região. De forma paralela aos projetos, foi discutida a história da cidade e dos nomes de algumas localidades que estão relacionados com a vegetação local, como por exemplo, o balneário de Guriri localizado no município. Ainda como proposta do laboratório, os alunos foram levados a uma sala de estudos do prédio da pós-graduação da Biodiversidade Tropical para assistirem um documentário produzido pela Reserva Natural Vale que retratava a importância da preservação da Mata Atlântica. Após esta atividade, os estudantes conheceram um projeto de estudo de fungos em pimenta-do-reino que era realizado por uma estudante de doutorado na Universidade.

\footnotetext{
${ }^{4} \mathrm{~A}$ agarose é um polissacarídeo que dissolve em água fervente que gelifica quando esfria como a gelatina. Para realizar uma eletroforese, um gel de agarose é preparado, o DNA é introduzido em pequenos poços de gel, e então uma corrente elétrica é aplicada através do gel. Como o DNA é negativamente carregado, ele é atraído pelo eletrodo positivo. Entretanto, para chegar ao eletrodo positivo, o DNA deve migrar através do gel de agarose. Os fragmentos de DNA normalmente são corados com brometo de etídio, que possui afinidade pelo DNA e torna-se visível em contato com a luz ultravioleta.
} 
Figura 3. A) Ephemeroptera visualizado a olho nu pelos alunos. B) Observação de Ephemeropteras com estereomicroscópio para melhor visualização de detalhes do corpo do inseto. C) Observando a variedade de espécies de cobras. D) Alunos manuseando as cobras. E) Alunos visualizando exsicatas de cacto e outras espécies. F) Aluno observando processo de eletroforese.
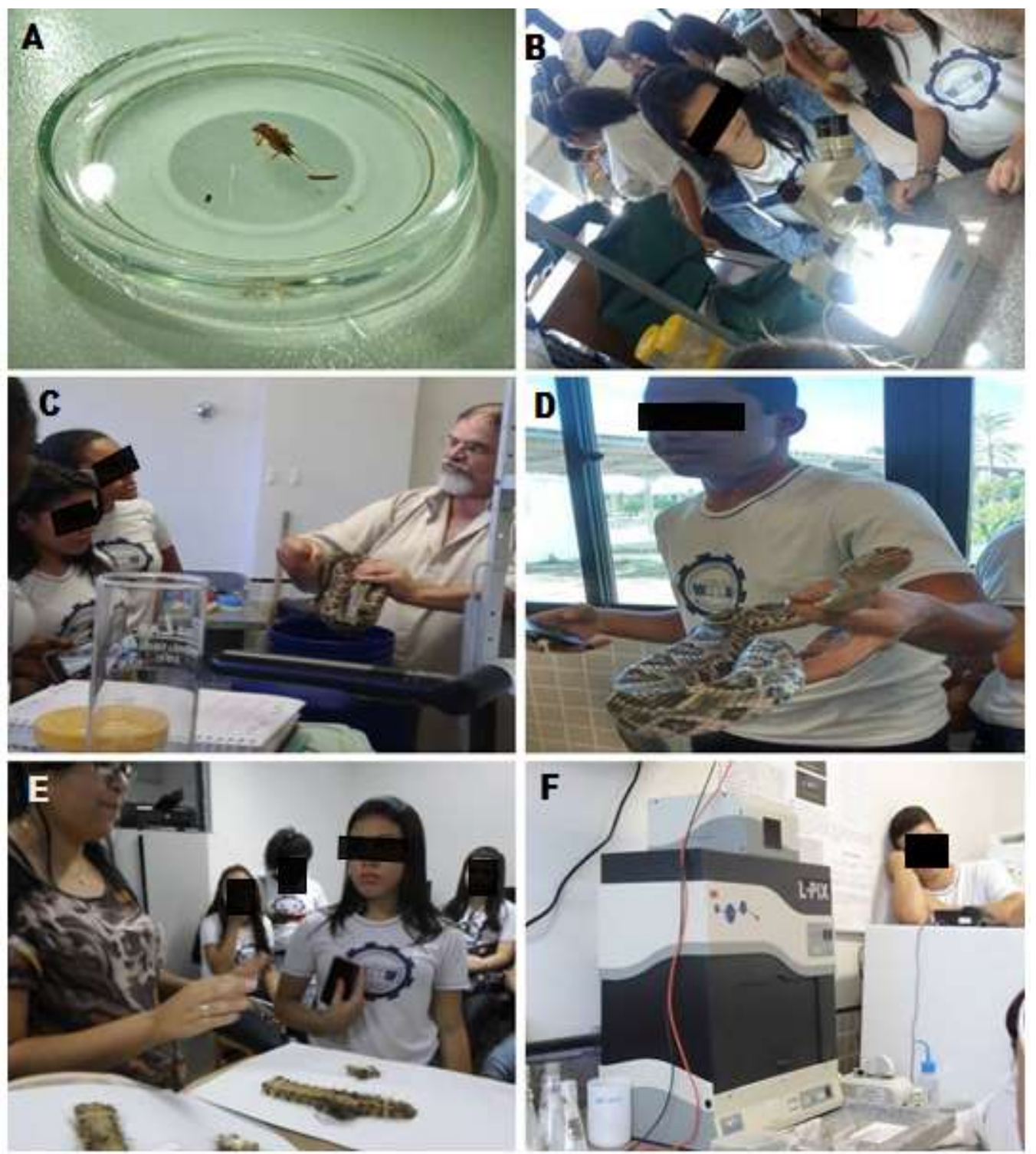

Fonte: Arquivo das autoras

- Laboratório de Vertebrados Aquáticos

Apresentou-se a diversidade de peixes de água doce da bacia do Rio São Mateus enfatizando a relevância desses estudos para o município e região. O professor responsável pelo laboratório e os graduandos discutiram junto aos estudantes do ensino médio temas diversos, dentre eles a inserção de espécies exóticas e suas consequências no ecossistema, importâncias 
econômicas e ambientais dos estudos com peixes. Por fim, observaram peixes de água doce em processo de diafanização ${ }^{5}$.

- Coleção Botânica

Os alunos foram levados ao herbário (Figura 4A) onde visualizaram as exsicatas (Figura 4B) de plantas e avaliaram a diversidade botânica da região e a importância de seu estudo e catalogação. Posteriormente, eles coletaram algumas plantas (Figura 4C) nas proximidades do herbário, seguindo as instruções do monitor e em seguida prensaram o material (Figura 4D).

- Orquidário

Os alunos visitaram o orquidário montado para pesquisas realizadas na área de Fisiologia Vegetal. Foi discutido o objetivo geral do projeto que visava avaliar a capacidade das orquídeas em alterar a sua fisiologia, morfologia e anatomia de acordo com as condições de luz do ambiente.

\section{- Coleção Zoológica}

Os estudantes conheceram a coleção zoológica que estava sendo montada na Universidade. Nesse ambiente, os alunos observaram peixes de água doce e marinhos (Figura 4E), invertebrados como libélulas, borboletas e besouros em caixas entomológicas (Figura 4F), dentre outros.

\footnotetext{
${ }^{5} \mathrm{~A}$ diafanização consiste na infiltração do tecido de seres vivos por um solvente da parafina que seja ao mesmo tempo desalcolizante. A parafina não se mistura com água e nem com álcool. Ambos devem ser completamente removidos para que a parafina possa penetrar eficientemente no tecido. O xilol é comumente utilizado. Tal produto químico é muitas vezes chamado de agente clarificador porque torna o tecido semitranslúcido, quase transparente, sendo possível estudar a anatomia interna do ser sem precisar abri-lo.
} 
Figura 4. A) Estudantes conhecendo a coleção botânica. B) Exsicatas pertencentes à coleção botânica. C) Alunos coletando plantas para realização de prensa. D) Alunos aprendendo técnicas de prensa de material coletado utilizadas para estudos botânicos.

E) Peixe marinho sendo apresentado aos alunos. F) Caixa entomológica com espécimes de borboletas, libélulas, besouros, dentre outros.
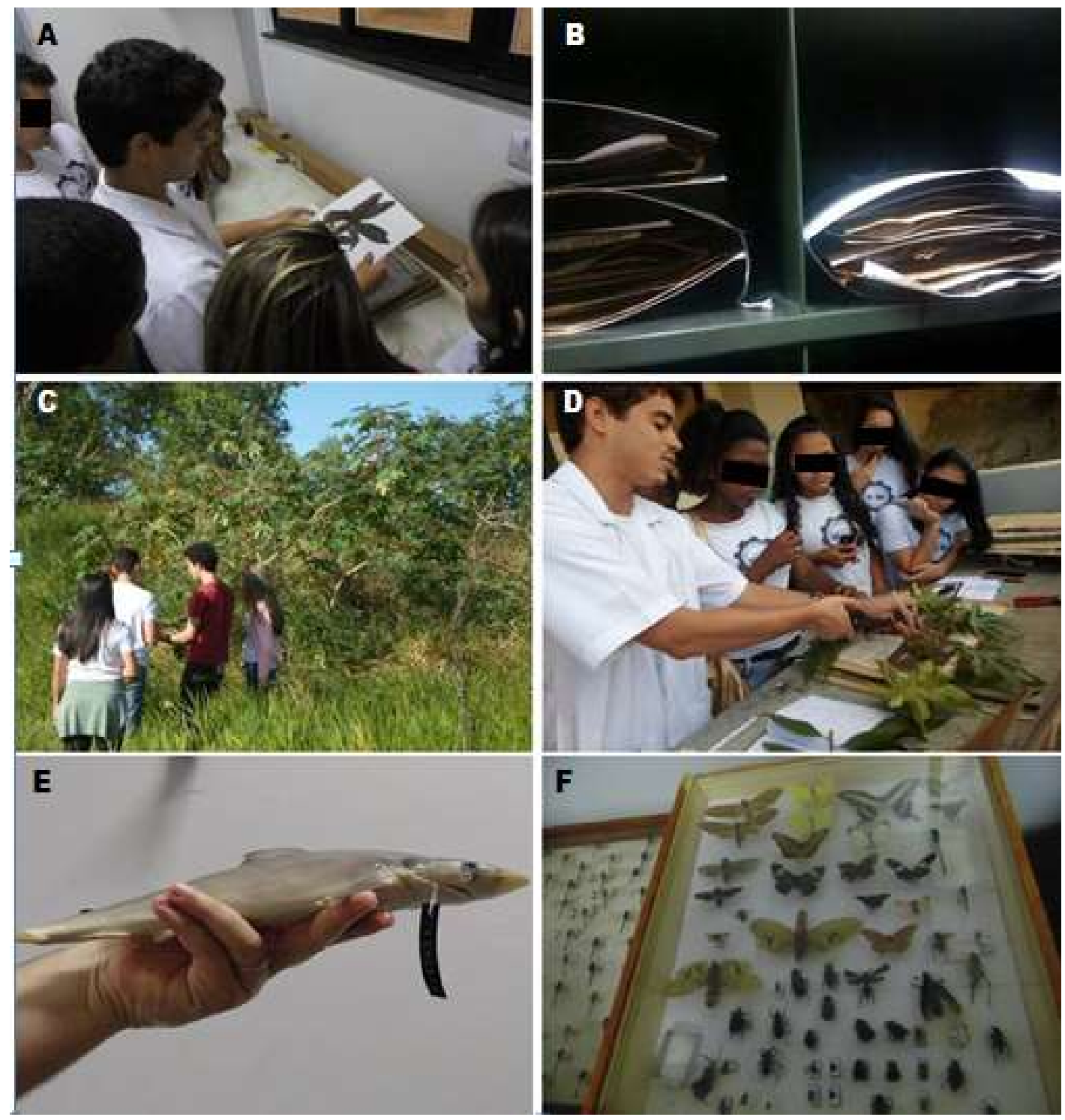

Fonte: Arquivo das autoras.

- Fazenda experimental

Os alunos tiveram a oportunidade de conhecer a Fazenda Experimental da UFES - campus São Mateus (Figura 5) e os projetos desenvolvidos por estudantes dos cursos de Agronomia e Ciências Biológicas. Durante a visita, um aluno do curso de Agronomia apresentou aos alunos visitantes o seu projeto de pesquisa sobre o desenvolvimento do milho em diferentes dosagens 
de nitrogênio e destacou a importância da biologia nesse projeto. Os estudantes conheceram várias espécies vegetais e compreenderam como os estudos sobre animais, vegetais, genética e fungos, dentre outros, são importantes na área agronômica.

Figura 5. Alunos durante a visita na fazenda experimental da UFES - campus São Mateus conhecendo os projetos que são realizados pelos estudantes de graduação e pós-graduação dos cursos de Agronomia e Ciências Biológicas.

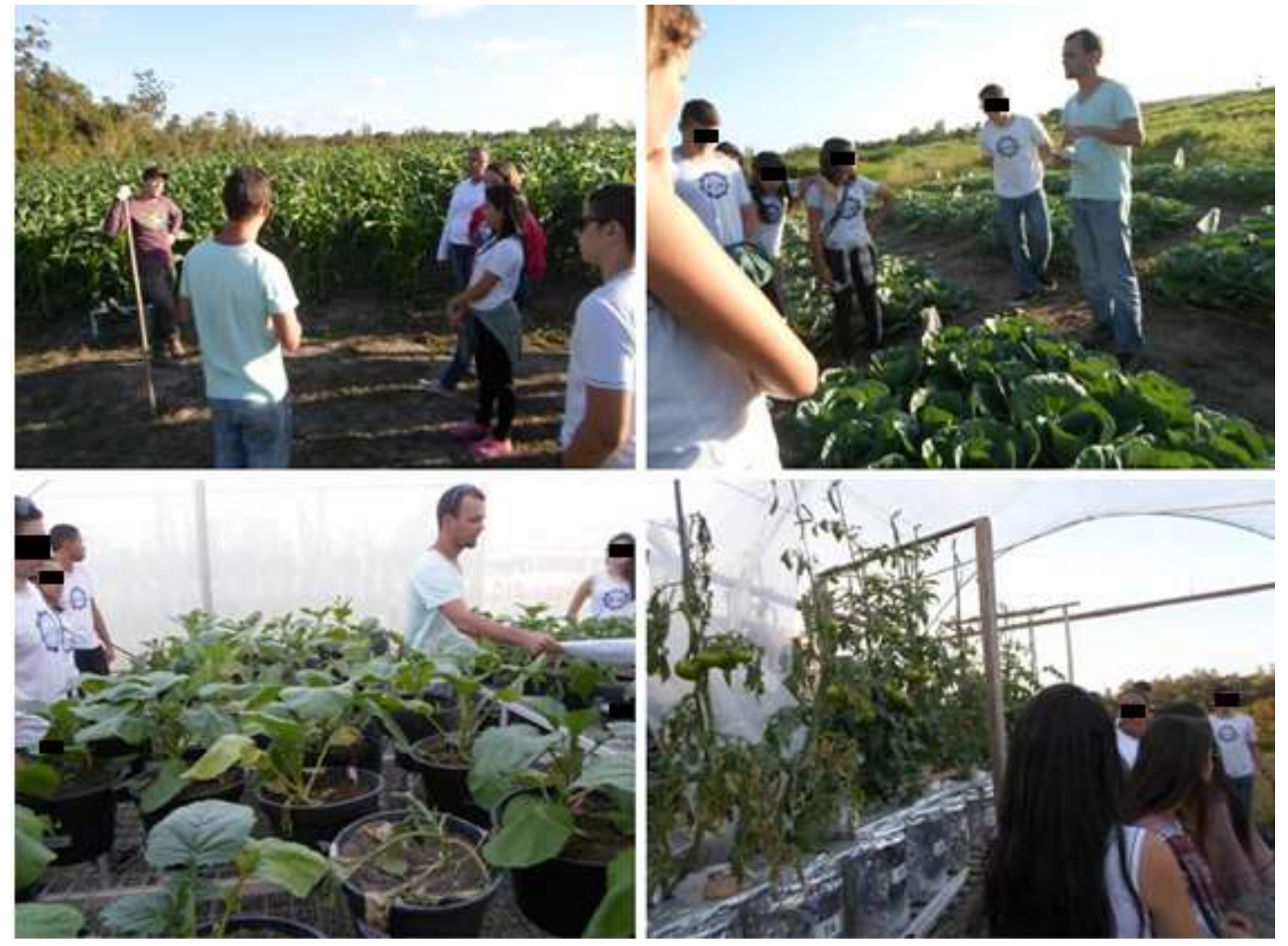

Fonte: Arquivo das autoras.

\section{Percepções dos estudantes acerca das atividades realizadas na UFES - campus São Mateus}

Antes dos estudantes participarem das atividades na Universidade e conhecerem os trabalhos científicos realizados, eles já haviam estabelecido seus (des)interesses e afinidades pela Biologia a partir de experiências escolares que tiveram ao longo de sua formação. Os estudantes relataram antes das visitas, na roda de conversa junto à pesquisadora, que as percepções que tinham da Biologia se baseavam em estudar plantas, animais, "ervilhas" (genética mendeliana), conservação ambiental e decorar conceitos. De acordo com Krasilchik (2008), os conceitos e termos passam a ter mais 
significado para o estudante quando ele consegue contextualizar o conteúdo com suas experiências pessoais. Assim, ao analisar os discursos dos estudantes, evidencia-se que o modelo descontextualizado de ensino adotado nas aulas de Biologia tende a dificultar o processo de ensino-aprendizagem distanciando o educando de seu objeto de estudo.

Os estudantes do Ensino Médio relataram também que consideram a Biologia complexa e, às vezes, tediosa de ser estudada pela pouca utilização de recursos didáticos, atividades diferenciadas e materiais expositivos durante as aulas. Uma pesquisa realizada por Coelho, Silva e Pirovani (2020) aponta quais recursos didáticos estudantes do ensino médio gostariam que fossem utilizados nas aulas de Biologia. Identificou-se que trabalho de cunho prático como laboratório para a realização de experiências, utilização de microscópio, aula de campo, visita a museus e utilização de materiais biológicos, sendo eles vivos ou fixados, estão na lista de preferências dos estudantes. Para o ensino de Biologia, Moreira e Diniz (2003) sinalizam a importância da experimentação afirmando que a prática permite que o estudante se envolva com os processos de produção científica e estimulam no estudante o senso de investigação, reflexão, análise crítica e criatividade. Além disso, possibilita o desenvolvimento da racionalidade científica e da popularização da ciência, a depender da abordagem adotada pelos professores durante as aulas.

Os relatos feitos pelos estudantes corroboram o que é discutido por Krasilchik (2008) quando afirma que a Biologia pode ser prazerosa ou insignificante e pouco atraente, dependendo do que é ensinado e de que modo isso é feito. Porém, apesar desta visão limitada da Biologia e da pouca diversificação das práticas educativas nas aulas, $56 \%$ dos estudantes afirmaram que gostam da área biológica e a consideram importante de ser estudada por tratar de assuntos do dia a dia e do corpo.

A experiência prática e contextualizada realizada com os estudantes possibilitou que estes revissem suas percepções sobre a Biologia. O Quadro 2 mostra as respostas obtidas através dos questionários. 
Quadro 2. Respostas dos estudantes do Ensino Médio quando questionados se mudaram sua percepção sobre a Biologia após a visita à UFES - Campus São Mateus.

\begin{tabular}{|c|c|l|}
\hline Categoria & Alunos (\%) & \multicolumn{1}{c|}{ Discursos } \\
\hline Não & 0 & \multicolumn{1}{c|}{-} \\
\hline Mais ou menos & 11 & $\begin{array}{l}\text { - "Gostei porque foi legal poder ver como tudo funciona, } \\
\text { mas continua complicada". } \\
\text { - "Porque achei um pouco entediante e muito } \\
\text { complicada algumas matérias". }\end{array}$ \\
\hline Sim & 89 & $\begin{array}{l}\text { - "Por causa dos professores da UFES e das aulas } \\
\text { práticas". } \\
\text { - "Porque vi a biologia de modo diferente, mais amplo, } \\
\text { divertido e de melhor entendimento". } \\
\text { - "Porque mostrou como o estudo da biologia é integrado } \\
\text { no nosso cotidiano". } \\
\text { - "Porque vi que não era um bicho de 7 cabeças, e que } \\
\text { existem vários fatores que definem a biologia". } \\
\text { - "Nós pudemos ver as coisas além do que elas são. } \\
\text { Nós não ficamos apenas nos livros e nas teorias, nós } \\
\text { vimos a biologia na própria prática". } \\
\text { - "Antes eu só gostava das coisas que envolviam o meio } \\
\text { ambiente, mas agora me interesso por outras áreas". }\end{array}$ \\
\hline
\end{tabular}

Fonte: autoria própria.

Após a atividade realizada, constatou-se que $89 \%$ dos alunos tiveram sua percepção sobre Biologia mudada. Os alunos foram apresentados às metodologias que são utilizadas para os estudos biológicos através da experimentação, juntamente com a discussão da importância que estes conhecimentos têm para o desenvolvimento e manutenção da vida na Terra. Freitas (2007) aponta a importância da compreensão e utilização dos conhecimentos científicos como base para a explicação do funcionamento do mundo e como os sujeitos, apropriados destes conhecimentos, podem e devem utilizá-los para intervir na sua realidade. Além disso, Del Pino e Frison (2011) descrevem a importância do entendimento dos princípios básicos de fenômenos do cotidiano na promoção da capacidade crítica de tomada de decisão em questões relativas à ciência e tecnologia.

Dentre os discursos dos estudantes que tiveram suas percepções mudadas acerca da Biologia, destacamos os que apontam a integração da biologia no nosso cotidiano'. De acordo com Krasilchik (2008), os conceitos e termos passam a ter mais significado para o estudante quando ele consegue contextualizar o conteúdo com suas experiências pessoais. Dentro de cada laboratório e após cada prática realizada com os estudantes, foram promovidas 
discussões sobre a aplicabilidade dos estudos realizados na vida cotidiana. Temas relacionados à produção agrícola, melhoramento genético de vegetais, preservação ambiental, diversidade biológica, saúde, dentre outros, que fazem parte do dia a dia das pessoas, foram discutidos à luz da ciência por professores, graduandos, pós-graduandos e técnicos da Universidade e os estudantes do ensino médio. Essa contextualização entre estudos científicos e codiano promoveu o interesse e a melhor compreensão dos estudantes sobre as temáticas abordadas.

A visita à UFES ofereceu a oportunidade de conhecerem uma Biologia que vai além daquela vista nos livros didáticos - que é identificado como o recurso didático mais utilizado nas aulas de Biologia na Educação Básica (ROSA, 2017). Investiu-se na apresentação de um conhecimento novo, o que ofereceu aos estudantes a oportunidade de vê-la como ciência e não apenas como matéria chata e complicada da escola, como é considerada por muitos.

Analisando o currículo de Biologia do Ensino Médio, identificamos a grande quantidade de conteúdos propostos dentro de uma carga horária insuficiente. Essa incompatibilidade de 'quantidade de conteúdo/tempo hábil' tende a limitar que o professor apresente exemplos e analogias diversificadas que proporcionem aos estudantes um melhor entendimento dos conceitos apresentados e a um aprendizado mais significativo, reflexivo e crítico (DURÉ; ANDRADE; ABÍLIO, 2018). Além disso, a diversificação das metodologias também ficam limitadas.

Nos discursos dos estudantes também foram destacados trechos como "não ficamos apenas nos livros e nas teorias". Quanto aos recursos didáticos utilizados no ensino de Biologia, a importância da experimentação é praticamente inquestionável (MOREIRA; DINIZ, 2003) uma vez que essa prática permite que o estudante compreenda as etapas do processo de produção científica. Segundo os estudantes, a realização de práticas foi um dos fatores que contribuiu para a compreensão da Biologia e mudança sobre a percepção que haviam da mesma. As atividades foram realizadas de forma descontraída e aberta ao diálogo de forma a despertar a curiosidade, interatividade e criticidade dos estudantes. Deste modo, estar em um 
laboratório e praticar a experimentação pode estimular no estudante o senso de investigação, reflexão, análise crítica, criatividade, além de resolver problemas com base nos conhecimentos adquiridos. Essa prática é orientada, inclusive, pela Base Nacional Comum Curricular (BRASIL, 2018).

Os estudantes também apresentaram mudanças quanto ao interesse por determinados conteúdos. Antes das visitas, os conteúdos que os estudantes mais apresentavam interesse na disciplina de Biologia eram corpo humano (anatomia e fisiologia), animais (zoologia) e genética, enquanto células (citologia) e plantas (botânica) eram os assuntos menos interessantes para eles. O interesse pelo estudo do corpo humano está relacionado à curiosidade dos alunos em conhecer a funcionalidade do seu corpo, suas características morfológicas e questões hereditárias. Segundo Malafaia, Bárbara e Rodrigues (2010) e Scheley, Silva e Campos (2014), os conteúdos vinculados à área de saúde, sexualidade e doenças, também aparecem como a área de maior interesse dos estudantes. Em relação ao conteúdo de zoologia (animais) o interesse pode ser explicado historicamente pela curiosidade que o homem tem sobre o comportamento dos animais, tanto para fins de domesticação, como forma de defesa ou simplesmente por querer conhecer a natureza animal (FARIAS, BESSA e ARNT, 2012 apud DEL-CLARO, 1997).

Em contrapartida, célula, uma estrutura microscópica, é uma entidade complexa e abstrata que se constrói em suas mentes (MOREIRA; PALMERO, 1999) e por esse motivo é tão dificilmente compreendida e apreciada pelos estudantes. A botânica, por sua vez, não atrai muito os estudantes, pois a maioria dos professores opta por utilizar a metodologia tradicional e de memorização, com a utilização de termos complexos que não fazem parte do vocabulário dos discentes. No norte do Estado do Espírito Santo a realidade encontrada é semelhante. Os recursos didáticos apontados como mais utilizados pelos professores ao ministrarem suas aulas de botânica são quadro e livro didático e poucos trabalham com recursos diferentes como microscópios, internet e aulas de campo (DUARTE-SILVA et al, 2014).

Considerando as respostas dadas à questão sobre as preferências dos temas da Biologia, do questionário aplicado após as visitas, "corpo humano" e 
"animal" continuaram sendo os conteúdos preferidos pela maioria dos estudantes, porém "plantas" e "célula" passaram a fazer parte de suas preferências. De forma geral, mesmo a biologia celular sendo considerada como um conteúdo abstrato pelos alunos, quando thes são oferecidos meios que os permitam ver como são essas estruturas, seja por microscópios ou modelos didáticos, os alunos se aproximam do assunto o que auxilia no processo de ensino/aprendizagem.

A botânica atraiu os alunos, pois, segundo eles, puderam conhecer os procedimentos que são utilizados para o estudo das plantas vendo a importância que elas possuem para nossa vida, afirmando, também, terem ficado surpresos com a quantidade de espécies presente em nossa região. Relacionadas ao ensino de botânica, uma série de práticas contextualizadas, com baixo ou nenhum custo, destinadas a professores de Ciências e Biologia do Norte do Espírito Santo já foram publicadas. Duarte-Silva, Silvério e Silva (2013) propuseram o ensino de ciclo de vida das angiospermas, mitose e meiose em plantas da Restinga e da feira livre de Guriri, município de São Mateus-ES; Duarte-Silva, Maciel e Sales (2014) identificaram elementos culinários comuns às culturas afro-brasileira, afro-caribenha e africana e elaboraram práticas de ensino tendo a alimentação em comum do Brasil, Caribe e África como elemento motivador para o ensino de Botânica e Zoologia; Duarte-Silva e colaboradores (2014) elaboraram e testaram uma aula de campo na llha de Guriri para o ensino da diversidade de Macroalgas, Fungos, Plantas e Animais. Deste modo, a botânica pode se tornar mais atraente para os estudantes se forem associadas às questões cotidianas e thes forem apresentadas sem a necessidade de decorar termos complexos que dificultam seu entendimento e o afastam da realidade.

O êxito no desenvolvimento dessa atividade pode estar atrelado ao fato de que o ensino por investigação, principalmente quando suas vertentes estão relacionadas com o trabalho experimental na educação científica, representa uma tentativa de superação da influência limitadora da prática pedagógica tradicional (MORI; CURVELO, 2018). As práticas experimentais que seguem o viés investigativo permitem que os alunos conheçam aspectos próprios da 
natureza das ciências como a heurística da modelagem, o caráter argumentativo da atividade científica e os condicionantes sociais das ciências de forma que apresentem a problematização de situações cotidianas e teste de hipóteses (KASSEBOEHMER; HARTWIG; FERREIRA, 2015).

Para além da Biologia, esta atividade permitiu a discussão da Ciência e do conhecimento científico de forma a promover o entendimento das relações entre ciência, tecnologia, sociedade e ambiente. Essa discussão, segundo Sasseron (2015), permite uma visão mais ampla e atualizada da ciência, evidenciando as complexas relações que envolvem o homem e a natureza e os impactos gerados pelo conhecimento científico sobre essas relações e os impactos que por elas são gerados.

\section{Considerações Finais}

Esta atividade foi desenvolvida de forma a possibilitar que estudantes do ensino médio pudessem, através da experiência científica universitária, vislumbrar a Biologia e o conhecimento científico de modo a modificarem e ampliares suas percepções acerca destes. Os estudantes tiveram a oportunidade de conhecer os procedimentos do trabalho técnico-científico e das pesquisas na área biológica e, ao abrir espaço para discutirem a utilização da ciência para fins sociais, permitiu-se a compreensão de sua importância para a manutenção e qualidade da vida na Terra.

Os estudantes mantiveram-se interessados e participaram ativamente das atividades, interagindo com os professores, técnicos, graduandos e pósgraduandos que os receberam nos laboratórios. Diante de seus relatos foi possível perceber que eles compreenderam como funcionam as pesquisas científicas, sobretudo na área de Biologia e como estes conhecimentos interferem diretamente no âmbito social e natural e se fazem presentes em seus cotidianos.

Neste sentido, visitas à Universidade e a realização de atividades investigativas dialogadas com a aplicabilidade dos conhecimentos científicos no cotidiano auxiliaram para a mudança na percepção dos estudantes sobre a Biologia, facilitando seu entendimento. Além disso, essa aproximação e o 
diálogo entre Universidade/Ensino Médio e experiência/ciência/práticas-docotidiano se mostraram ferramentas eficazes para o desenvolvimento crítico cidadão dos estudantes possibilitando que, através do conhecimento científico, possam projetar sua atuação responsável na sociedade em que vivem reconhecendo seus problemas e ajudando a enfrentá-los.

\section{Referências}

ARAÚJO, L. F. S.; DOLINA, J. V.; PETEAN, E,; MUSQUIM, C. A.; BELLATO, R.; LUCIETTO, G. C. Diário de pesquisa e suas potencialidades na pesquisa qualitativa em saúde. Revista Brasileira Pesquisa Saúde, Vitória-ES, p. 5361, jul./set. 2013.

BRASIL. Ministério da Educação. Secretaria da Educação Básica. Base Nacional Comum Curricular: educação é a base. Brasília: Ministério da Educação, Secretaria de Educação Básica, 2018. Disponível em: http://basenacionalcomum.mec.gov.br/wpcontent/uploads/2018/12/BNCC 19dez2018 site.pdf. Acesso em: 23 mai. 2021.

CACHAPUZ, A. et al. (Org.). A necessária renovação do ensino das ciências. São Paulo: Cortez, 2005.

CHASSOT, A. I. Alfabetização científica: uma possibilidade para a inclusão social. Revista Brasileira de Educação, São Paulo, v. 23, n.22, p. 89-100, 2003. Disponível em: https://www.scielo.br/pdf/rbedu/n22/n22a09. Acesso em: 15 jan 2020.

COELHO, F. T.; SILVA, E. D.; PIROVANI, J. C. M. Percepção de estudantes do ensino médio de uma escola pública do Espírito Santo sobre o ensino de Biologia: desejos e realidades. Olhares \& Trilhas, Uberlândia - MG, vol.22, n. 3, 2020. DOI https://doi.org/10.14393/OT2020v22.n.3.57134

DEL PINO, J. C.; FRISON, M. D. Química: um conhecimento científico para a formação do cidadão. Revista de Educação, Ciências e Matemática, v. 1, p. 36-50, $2011 . \quad$ Disponível em: http://publicacoes.unigranrio.edu.br/index.php/recm/article/view/1585. Acesso em: 3 jun 2020.

DUARTE-SILVA, É.; MACIEL, T. S.; SALES, P. A. Práticas de Ensino em Biologia envolvendo conexões culturais do Brasil com o Caribe. Revista Congreso Universidad, v. 3, p. 58, 2014.

DUARTE-SILVA, É.; SILVÉRIO, A.; SILVA, A. M. H. D. Teaching Meiosis and Mitosis in Schools of developing countries: How to improve education with a plant reproduction project. 1. ed. Rijeka: In Tech, v. 1. 2013. 20p. 
DUARTE-SILVA, É.; SOUZA, W. O.; MACHADO, J. O.; TESCH, F.; FURIERI, K. S. Recursos didáticos utilizados pelos professores de Ciências e Biologia e orientações de Prática de Ensino a baixo custo na ilha de Guriri, São MateusES, Brasil. Anais do Congresso do Setor de Ciências Agrárias e Ambientais da UNICENTRO, v. 2, 2014. p. 166-14.

DURÉ, R. C.; ANDRADE, M. J. D. ; ABILIO, F. J. P. Ensino de biologia e contextualização do conteúdo: quais temas o aluno de ensino médio relaciona com o seu cotidiano?. Experiências em ensino de ciências (UFRGS), v. 13, p. 259-272, 2018. Disponível em: http://if.ufmt.br/eenci/artigos/Artigo ID471/v13 n1 a2018.pdf. Acesso em: 28 fev 2020.

FARIAS J. G.; BESSA, E.; ARNT, A. M. Comportamento animal no ensino de Biologia: possibilidades e alternativas a partir da análise de livros didáticos de Ensino Médio. Revista Electrónica de las Ciências. Vol 11, N.2. p. 365-384. 2012.

em: http://reec.uvigo.es/volumenes/volumen11/REEC 1126 ex559.pdf. Acesso em: 14 jan 2020.

FERNANDES, H. L. Um naturalista na sala de aula. Ciência \& Ensino. Campinas, Vol. 5, 1998.

FREITAS, O. Equipamentos e Materiais Didáticos. Brasília: Universidade de Brasília, 2007.

KASSEBOEHMER, A. C.; HARTWIG, D. R.; FERREIRA, L. H. Contém química 2: pensar, fazer e aprender pelo método investigativo. 2. ed. São Carlos: Pedro \& João. 2015.

KRASILCHIK, M. Práticas de Ensino de Biologia. $4^{a}$.ed. ver. e ampl., $2^{a}$ reimpr. - São Paulo: Editora da Universidade de São Paulo, 2008.

Reformas e realidade: o caso do ensino das ciências. São Paulo em Perspectiva, São Paulo, v. 14, n. 1, p. 85-93, 2000. Disponível em: https://www.scielo.br/pdf/spp/v14n1/9805.pdf. Acesso em: 27 jun 2020.

MALAFAIA, G., BÁRBARA, V. F., RODRIGUES, A. S. L. Análise das concepções e opiniões de discentes sobre o ensino da Biologia. Revista Eletrônica de Educação, v. 4, n. 2, 2010. Disponível em: http://www.reveduc.ufscar.br/index.php/reveduc/article/view/94. Acesso em: 05 jun 2020.

MEDEIROS, F. V. G. de; CATUNDA, A. G. V.; RODRIGUES, M. J. A. M; CAVALCANTE, C. A. M. Análise da práxis docente em Biologia no ensino secundário português. Ciência e Educação (UNESP), v. 23, p. 341-356, 2017. Disponível em: https://www.scielo.br/scielo.php?script=sci arttext\&pid=S151673132017000200341. Acesso em: 15 jun 2020. 
MOREIRA, I. C. A inclusão social e a popularização da ciência e tecnologia no Brasil. Inclusão Social, Vol. 1, n. 2. p. 11-16, 2006. Disponível em: http://revista.ibict.br/inclusao/article/view/1512/1708. Acesso em: 20 jun 2020.

MOREIRA, M. L.; DINIZ, R. E. S. O laboratório de Biologia no Ensino Médio: Infra-estrutura e outros aspectos relevantes. In: UNIVERSIDADE ESTADUAL PAULISTA - Pró-Reitoria de Graduação (org.), Núcleos de Ensino. São Paulo: Editora da UNESP, 2003, p. 295-305.

MOREIRA, M. A.; PALMERO, M. L. R. Modelos mentales de la estructura y funcionamiento de la célula. Investigações em Ensino de Ciências, Porto Alegre, v. 4, n.2, p. 121-160, 1999.

MORI, R. C.; CURVELO, A. A. S. A Experimentoteca do Centro de Divulgação Científica e Cultural (CDCC-USP) e o Ensino por Investigação: Compromissos Teóricos e Esforços Práticos. Revista Brasileira de Pesquisa em Educação em Ciências. v. 18. n. 3, p. 795-818, 2018.

RIBEIRO, F. F.; AOYAMA, E. M., TEIXEIRA, M. C.; MENEZES, L. F. T. A Universidade como espaço complementar ao Ensino de Botânica no Ensino Médio. Kiri-Kerê - Pesquisa em Ensino, v. 1 n. 9. 2020. DOI: 10.47456/krkr.v1i9.28688

ROSA, M. D. O uso do livro didático de ciências: uma revisão dos trabalhos publicados. Contexto \& Educação, v. 32, p. 55-86, 2017. Disponível em: https://revistas.unijui.edu.br/index.php/contextoeducacao/article/view/6787. Acesso em: 26 dez. 2019.

SASSERON, L. H. Alfabetização científica, ensino por investigação e argumentação: relações entre ciências da natureza e escola. Revista Ensaio. Belo Horizonte, v.17 n. especial. p. 49-67. 2015. Disponível em: https://www.scielo.br/pdf/epec/v17nspe/1983-2117-epec-17-0s-00049.pdf. Acessado em: 03 jul. 2020.

SCHELEY, T. R.; SILVA, C. R. P.; CAMPOS, L. M. L. A motivação para aprender Biologia: o que revelam alunos do ensino médio. Revista de Ensino de Biologia da Associação Brasileira de Ensino de Biologia, v. 7, p. 49654974 , 2014. Disponível em: https://repositorio.unesp.br/bitstream/handle/11449/135430/ISSN1982-18672014-07-4965-4974. pdf? sequence=1\&isAllowed=y. Acessado em: 03 jan. 2020.

\section{Sobre os autores}

\section{Fernanda Tesch Coelho}

fernandac.tesch@gmail.com

Graduada em Licenciatura em Ciências Biológicas (2015), especialista em Educação do Campo (2016) pela Multivix - Campus São Mateus, mestrado em Ensino na Educação Básica (2017) pela Universidade Federal do Espírito Santo (UFES), campus Centro Universitário Norte do Espírito Santo 
(CEUNES). Atuou como professora substituta no CEUNES/UFES no período de 2018 a 2020. Atualmente, atua como professora contratada do ensino médio pela Secretaria de Estado da Educação (SEDU) do estado do Espírito Santo.

\section{Érica Duarte Silva}

profaericaduartesilva@gmail.com

Bacharel em Ciências Biológicas pela Universidade Federal de Juiz de Fora (UFJF), Minas Gerais. Bacharel em Turismo pela Fundação Educação São José em Santos Dumont (FESJ), Minas Gerais. Especialista em Gestão Ambiental pela UFJF. Mestre em Botânica pela Universidade Federal de Viçosa (UFV), Minas Gerais. Doutora em Ciências: Botânica pela Universidade Federal do Rio Grande do Sul (UFRGS), com estágios no Laboratório de Citogenética Molecular Vegetal da Universidade Estadual de Londrina (UEL), Paraná e no Herbário do Museu Nacional de História Natural em Paris, França. Foi professora temporária do Instituto de Educação da FESJ e do Ufes, onde atuou com Botânica, Ensino de Ciências e Biologia e Educação Ambiental. É professora adjunta da Universidade Federal do Espírito Santo, Campus São Mateus, do Departamento de Ciências Agrárias e Biológicas, na área de Ensino de Botânica. Atua nas áreas de Educação Ambiental, Ensino de Ciências e Biologia, e Antropologia Educacional. É coordenadora do Laboratório de Sociologia e Antropologia aplicado a prática de ensino do Núcleo de Pesquisa e práticas pedagógicas em Ensino de Biologia e Educação Ambiental (NPPBIO-Ufes, Campus São Mateus).

\section{Juliana Castro Monteiro Pirovani}

juliana.pirovani@ufes.br

Bióloga (bacharelado e licenciatura) pela Universidade Federal de Viçosa (2005), mestre (2007) e doutora (2010) em Biologia Celular e Estrutural pelo Programa dePós-graduação em Biologia Celular e Estrutural da Universidade Estadual de Campinas. É professora associada da Universidade Federal do Espírito Santo, lotada no Departamento de Ciências Agrárias e Biológicas (UFES - Campus São Mateus). Professora Permanente do Programa de Pósgraduação Mestrado Profissional em Rede Nacional (PROFBIO) da Universidade Federal do Espírito Santo (UFES - Campus de São Mateus). Tem experiência na área de Morfologia, Toxicologia Reprodutiva, Ecotoxicologia e Ensino de Ciências e Biologia. 